\title{
Links between Developmental Change in Kindergarten Behaviors and Later Peer Associations
}

\author{
Linda S. Pagani ph.D. (Corresponding author) \\ École de psychoéducation, Campus Laval, Université de Montréal \\ C.P. 6128, succursale Centre-ville, Montréal, Québec, H3C 3J7, Canada \\ Tel: 1-514-343-6111 E-mail: Linda.S.Pagani@umontreal.ca \\ Anne-Julie Allard MSc. \\ École de Psychoéducation and Centre Hospitalier Universitaire Sainte-Justine \\ Université de Montréal, Canada
}

Received: August 27, 2011

Accepted: November 25, 2011

Published: December 30, 2011

doi:10.5539/jedp.v1n1p45

URL: http://dx.doi.org/10.5539/jedp.v1n1p45

This research was supported by Canada's Social Science and Humanities Research Council (SSHRC).

\begin{abstract}
Using secondary analysis of existing data from the Montreal Longitudinal Preschool Study (MLPS, Canada), we examine the basic influence of early behavioral change upon later peer affiliation at the end of elementary school. We also verify the reliable nature of the teacher-ratings, as a more cost-effective alternative to socio-metric measures. Key child variables and their sources include kindergarten teacher-ratings of social skills and classroom behaviors. Results revealed prospective associations between teacher-ratings of children's general ability to get along with peers and later peer affiliations. Results also revealed prospective associations between early natural occurring change in child cognitive and socio-emotional behaviors during the kindergarten year and later affiliations with popular, deviant, and rejected peers. These issues are above and beyond the influence of family characteristics and baseline cognitive and behavioral characteristics. Our findings have promising implications for contrived change resulting from interventions directed at behavioral change.
\end{abstract}

Keywords: Peer affiliation, Developmental change, Teacher-ratings, Early social behaviors

\section{Introduction}

School entry represents the earliest moment when children become regularly grouped into social units with a structure and function aimed at learning and personal development. It is also a time when young children begin to advance their comprehension of others and the intentions, desires, emotions, and beliefs that cause people to act as they do (Garon, Bryson, \& Smith, 2008; High \& the Committee on Early Childhood, Adoption, and Dependent Care and Council on School Health, 2008; Shonkoff, \& Phillips, 2000). Such developmental achievements are important because early individual differences in social and emotional competence have an influence upon the way children get along with their classmates.

Research has clearly demonstrated that both externalizing (e.g., impulsivity and aggression) and internalizing behaviors (e.g., anxiety and depression) are associated with deviant peer associations and peer rejection (Parker \& Asher, 1987; Ladd, 1990). Peer relations in childhood are important because they predict short- and long-term adjustment and, when friends are deviant in nature; they predict later school truancy, school suspension, delinquency, school dropout, and involvement with law enforcement in adolescence (Collins \& Van Dulmen, 2006; Loeber \& Southamer-Loeber, 1998). Affiliating with deviant people often results in peer deviancy training, which maintains the acquisition of conduct problems, such as stealing, drug use, vandalism, and truancy (Goldstein, Davis-Kean, \& Eccles, 2005)

Conversely, prosocial behavior is associated with positive peer affiliations. Studies suggest the buffering effects of positive peer relationships in childhood, including reduced levels of anxiety and depression, loneliness, and 
aggressive behavior (Coie, Lochman, Terry, Hyman, 1992; Erdley, Nangle, Newman, \& Carpenter, 2001). In addition, positive peer relationships are associated with increased self-esteem and more effective social problem-solving (Bukowski, Hoza, \& Boivin, 1993). Most importantly, positive peer relations are a protective factor in that they influence the likelihood of high school graduation in disadvantaged boys (Vérroneau, Vitaro, Pederson, \& Tremblay, 2008). As such, early social-emotional behaviors are likely key elements for children's positive social development in the classroom (Pagani, Fitzpatrick, Archambault, \& Janosz, 2010).

In this paper, we propose that how children are getting along with their classmates at school entry represents an important aspect of school readiness, especially because early peer affiliations have been linked with academic success in disadvantaged environments (Vérroneau et al., 2008). It could be reasonably argued that behavioral development at school entry (such as hyperactive, aggressive, inattentive, emotionally-distressed, and prosocial behaviors) influences overall adjustment and, in turn, the way children are treated by others (Pagani et al., 2007). Ultimately, information on the influence of developmental change during kindergarten could have implications for interventions that aim to promote later social adjustment via early behavioral change (Pagani et al., 2010). These also aim to avoid the consequences associated with negative peer affiliations. Such research would help focus energy and resources where they would be most effective and cost-efficient.

We begin by verifying the reliable nature of the teacher-ratings used in this study. To do so, we test the influence of general kindergarten social skills, measured by teacher-ratings of getting along with peers, upon subsequent peer affiliations at the end of elementary school. The predictive power of estimating from one general question to teachers has never been studied in the past literature. As such, its use provides a test of robustness of how well this measure, as a more cost-effective alternative to socio-metric measures that are typically used in social research settings, prospectively predicts peer affiliations six years later. We then examine the basic influence of behavioral change from the beginning to the end of kindergarten upon later peer affiliation, in order to facilitate a better understanding of preventive interventions and their influence upon later behavioral development.

\section{Methods}

\subsection{Participants}

This study uses data from the Montreal Longitudinal Preschool Study (MLPS), launched in 1997, comprising five cohorts with French-speaking children from the poorest neighborhoods of Montreal. The original sample of 4- and 5-year-olds was obtained after a multilevel consent process involving school board officials, local school committees, and parents and teachers after informing them about the longitudinal nature of the project. Our sample used comprises two sequential child cohorts from MLEPS that began kindergarten in fall of 1998 and in fall of 1999. Initial $(N=1369)$ and follow-up $(n=1102)$ data were collected from multiple sources, including direct cognitive assessments of children, and surveys of parents and teachers. Follow-up measures in both grades 5 (for the 1998 cohort) and 6 (1999 the cohort) represent 80\% of the initial sample. Attrition analyses do not reveal significant differences between retained and non retained data.

\subsection{Measures: Independent Variables}

Social Skills. At the end of kindergarten, using Social Behavior Questionnaire (SBQ), teachers rated participants on one item regarding "getting along with classmates". Their response options, ranging on a Likert scale, went from excellent, good, average, weak, to very weak.

Social Behavior Questionnaire. This study collected teacher-ratings at the beginning and end of kindergarten using the SBQ was developed by Tremblay, Offord, and Boyle for the National Longitudinal Study of Children and Youth (NLSCY). The items assess children's behavioral adjustment and originate from the Ontario Child Health Study (Directed by David Offord) and the Montreal Longitudinal-Experimental Study of Kindergarten Boys (Directed by Richard E. Tremblay). Item response options, ranging on a Likert scale, are from never/false, sometimes or often/true. Norms are available from ages 4 to 11: Emotionally-Distressed ( 8 items, alpha at age 4 $=.85$ ); Physically Aggressive (6 items, alpha at age $4=.87$ ); Hyperactive ( 8 items, alpha at age $4=.93$ ); Inattentive ( 4 items, alpha at age $4=.82$ ) and Prosocial Behavior (10 items, alpha at age $4=.92$ ). This early childhood behavioral assessment takes 15 minutes to complete and represents a good predictor of later psycho-social adjustment Dobkin, Tremblay, \& Masse, \& Vitaro, 1995; Tremblay, Pihl, Vitaro, \& Dobkin, 1994; Kerr, Tremblay, Pagani, \& Vitaro, 1997) and academic attainment by age 22 (Vitaro, Brendgen, Larose, \& Tremblay, 2005).

\subsection{Measures: Dependant Variable}

Participants from both child cohorts (in grades 5 and grade 6) were rated by their teachers on their peer associations. The items were been regrouped into three scales representing the kind of peers participants 
typically associate with at school. Responses ranged from never/false, sometimes, always/true. We obtained satisfactory to excellent Crohnbach alphas: Popular Peer Affiliations (is popular with high achieving fiends; is popular with athletic friends; gets along with peers or classmates; Crohnbach alpha $=.66$ ); Deviant Peer Affiliations (hangs out with kids who get in trouble; does delinquent activity with friends; is popular with deviant friends; Crohnbach alpha $=.83$ ); and Rejecting Peer Affiliations (felt rejected by his/her peers or classmates; you witnessed incidents or peer rejection; Crohnbach alpha $=.86$ ).

\subsection{Measures: Control Variables}

In all analyses estimating the influence of social skills on subsequent peer affiliations, we control for family configuration (sole parenting versus intact family) and maternal education (not finishing high school versus finishing) as reported by mothers, and child characteristics such as sex and behavioral characteristics (emotionally-distressed, physically aggressive, hyperactive, inattentive, and prosocial behaviors) as reported by teachers at the beginning of the kindergarten school year. All analyses also control for children's cognitive skills at the beginning of kindergarten: (1) Peabody Picture Vocabulary Test (PPVT, Dunn, Thériault-Walen, \& Dunn, 1993). To control for cognitive verbal skills, the French PPVT, forms A and B, was individually administered in kindergarten to assess children's receptive verbal skills, which represent an important indicator of intellectual development and school readiness. Trained examiners administered this test at the beginning of junior kindergarten. Individual administration takes approximately 8-10 minutes. (2) Number Knowledge Test (NKT). To control for cognitive mathematic skills, the NKT represents an individually administered assessment of children's informal knowledge of number and conceptual prerequisites of pre-arithmetic operations. Norms were developed by Robbie Case for age levels corresponding from 4 through 10 for both low- and middle-income children from Ontario, Massachusetts, Oregon, and California (Okamoto \& Case, 1996). Our short-version was developed in collaboration with Robbie Case, and is predictive of academic performance in the middle grades (Duncan et al., 2007; Pagani et al., 2010). The NKT has been found to predict third grade academic performance as well as the PPVT. It also predicts third grade reading as well as it predicts math. Trained examiners administered this test at the beginning of kindergarten. The test measures the five conceptual prerequisites and total time for individual administration and scoring of this test is 15 to 20 minutes.

\subsection{Data Analytic Strategy}

Replicating a data analytic strategy from previous school readiness work using the MLPS (Duncan et al., 2007; Pagani et al., 2010), we first conducted a series of Ordinary Least Squares (OLS) Multiple Regressions to examine the reliability of the kindergarten teacher-rating approach to the relationship between children's social skills (ability to get along with peers, GAP) and later peer associations (PeerChar) at the end of elementary school, while controlling for any possible direct or indirect influences of family (maternal education and family configuration) and child (sex, NKT, PPVT, and social behaviors at the beginning of kindergarten) characteristics. The analytic strategy relates peer affiliation characteristics measured at the end of elementary school (PRIM) to our general measure of social skills (as a reflection of peer relations), rated by teachers at school entry. Our results bear upon this fully controlled equation, where "a" and "e" represent the intercept and stochastic error, respectively:

$$
\text { PeerChar }_{\text {iPRIM }}=\mathrm{a}_{1}+\beta_{1} \mathrm{GAP}_{\mathrm{iSK}}+\gamma_{1} \mathrm{FAM}_{\mathrm{i}}+\gamma_{2} \text { CHILD }_{\mathrm{i}}+\mathrm{e}_{\mathrm{it}} .
$$

Second, we examined whether a developmental change in socio-cognitive behaviors, controlling for the child characteristics (sex and cognitive skills) and the aforementioned family characteristics, has an influence on the kind of peer groups the child associates with at the end of elementary school. Because the amount of change might likely be influenced by the baseline level of a behavior when the child starts kindergarten (i.e., children with low (floor) or high (ceiling) levels of a behavior may not decrease/increase very much compared to children who do not present such extreme starting level characteristics, we also added a baseline control for each behavior using beginning of kindergarten scores (e.g., hyperactive behavior at the beginning of kindergarten for change model on hyperactive behavior in kindergarten). This reduces interpersonal variation on this variable at kindergarten entry and allows us to study the influence of a developmental change on a particular variable without the confounding influence of individual baseline differences. Change scores $(\triangle \mathrm{BEH})$ which estimate the variation in child social behaviors in kindergarten were generated using a two step process. We first subtracted scores of the beginning of kindergarten from scores of the end of kindergarten. We then used change scores as predictors in a series of OLS regressions, while discounting the influence of the aforementioned child and family characteristics at kindergarten entry. Our results bear upon this fully controlled equation: PeerChar $_{\text {iPRIM }}=b_{1}+\delta_{1}$ $\Delta \mathrm{BEH}_{\mathrm{i}}+\delta_{2} \mathrm{BEH}_{\mathrm{iFK}}{ }^{+} \quad \gamma_{1} \mathrm{FAM}_{\mathrm{i}}+\gamma_{2} \mathrm{CHILD}_{\mathrm{i}}+\eta_{\mathrm{it}}$, where $\mathrm{b}_{1}$ and $\eta_{\mathrm{it}}$ represent a constant and stochastic error term, respectively. 


\section{Results}

Descriptive statistics for the pertinent child and family characteristics are reported in Tables 1 and 2. Results from Table 3 indicate that the general ability to get along with peers, measured by teachers at the end of kindergarten, was prospectively associated with popular peer affiliation at the end of elementary school $(\beta=.25$, $t(11,39)=4,40 p \leq .01)$. Specifically, a one unit increase general social skills during kindergarten predicted a .25 unit increase in later teacher-reported relationships with popular peers $(S E=.91)$, holding all other child and family variables in the model constant. The general social skills variable was also prospectively associated with a lesser likelihood of deviant peer affiliation at the end of elementary school $(\beta=-.18, t(11,39)=-3,10 p \leq .05)$ $(S E=.93)$. Finally, this variable also predicted a lower likelihood of affiliating with rejected peers at the end of elementary school $(\beta=-.24, t(11,39)=-4,19 p \leq .01)(S E=.95)$. These three relationships are above and beyond the competing influence of theoretically and statistically pertinent family and child cognitive and behavioral characteristics.

Table 4 reports descriptive statistics for the change scores on each social behavior and Table 5 reports results of the OLS regressions pertaining to the three outcomes, respectively. First, an increase in hyperactive behavior ( $\beta$ $=-.15, t(11,40)=-2,84 p \leq .01)$ during kindergarten predicted a lower propensity of affiliating with popular peers at the end of elementary school. That is, a one unit increase in this developmental change in hyperactive behavior from the beginning to the end of kindergarten was prospectively associated with a .15 unit lesser likelihood of having popular friends $(S E=.91)$, while holding all other variables in the model constant. Also, a decrease in inattention $(\beta=.17, t(11,40)=3,40 p \leq .01)$ during kindergarten predicted a greater propensity to associate with popular peers in grades 5 and $6(S E=.91)$. Second, Table 6 reports that increments in both hyperactive $(\beta=.13, t(11,40)=2,50 p \leq .01)$ and aggressive behavior $(\beta=.13, t(11,40)=2,53 p \leq .01)$ during kindergarten predicted increased chances of later deviant peer affiliations at the end of elementary school $(S E=.93)$. Finally, Table 7 reports that increments in hyperactive beh-avior $(\beta=.11, t(11,40)=2,03 p \leq .05)$ in kindergarten predicted affiliating with rejected peers at the end of elementary school. Noteworthy is that decrements in inattention $(\beta=-.13, t(11,40)=-2,38 p \leq .05)$ during kindergarten was prospectively associated with a lesser likelihood of rejected peer affiliations in grades 5 and $6(S E=.91)$.

\section{Discussion}

Numerous preventive programs are available, especially in elementary school. Programs often try to improve child social adjustment via early behavioral change. These programs require a lot of people, time, money, and energy. Links between children's behavior and peer associations have been well established, yet few have applied a developmental model of the influence of kindergarten teacher-ratings upon later child peer affiliations. Is it worthwhile for young children to get involved in psychosocial interventions when childhood is supposed to be a time of informal learning and play? This paper suggests how efficient early childhood behavioral change during a critical life course turning point when programs could have optimal results because the children are still young and have not yet faced the academic challenges of the elementary school curriculum. Given the implications of prediction models, our findings allow us to speculate how an induced change, resulting from an early childhood intervention, might have an effect on later behavior.

First, this study confirms the predictive power of non-sociometric and thus less expensive assessments, like teacher ratings, as an assessment of social competence at school entry. We must emphasize that our findings do not reflect socio-metric measures and that our hypotheses were tempered by that limitation. Nevertheless, teacher-ratings were sensitive in detecting the influence of change, above and beyond a number of conservative controls as maternal education, sole parenting, and baseline emotionally-distressed, physically aggressive, hyperactive, inattentive, and prosocial child behaviors. Change models, where end of school scores are subtracted from beginning of school scores, must have baseline values controlled because the size of the measured change can be influenced by extremes in their baseline values. For example, a child with low hyperactive behavior does not have very far to go to stay low and adaptive. Such high scores do not leave much room for change compared to children who start high. Children with higher scores would have inflated estimates of change because they have more room for a bigger drop than their counterparts who start low already.

Second, the old adage, "As the twig is bent, the tree inclines", speaks directly to our results. As expected, we found that, according to kindergarten teacher-ratings, developmental change in behavioral characteristics such as hyperactive, aggressive, and inattentive behavior forecasted what kind of friends children would be associating with by the end of elementary school. The concept of homophily could explain the process of peer affiliation. According to propensity theory (Jessor, 1998), youth with similar behavioral characteristics (hyperactivity, aggression) habitually have greater chances of sharing similar interests and activities, which are related to 
delinquency. Conversely, hyperactivity and inattention could lead to rejection because of the aversive conducts these behaviors could involve. Hyperactive children are often socially turbulent and inattention could be perceived as a lack of interest for others (Barkely, 2012). However, children who develop their attention skills pay more attention to others intentions, feelings, and desires. Then, they become more attractive because they harbor more prosocial skills (Barkely, 2012). Our results suggest a natural occurring change in early socio-cognitive behaviors which have an influence on later peer affiliations and social adjustment. What could have influenced the change? Maturational processes could explain the naturally occurring change in child aggressive, hyperactive, and inattentive behavior in kindergarten. Generally, aggression, hyperactivity and inattention develop intensively from birth to 5 years old and remain quite stable during childhood, pre-adolescence, and adolescence (Barkely, 2012; Côté, Vaillancourt, LeBlanc, Nagin, \& Tremblay, 2006; Pagani et al., 2007; Ruff \& Rothbart, 1996).

Low socioeconomic status (SES) and the effect of grouping similar peers in kindergarten could also explain the naturally occurring change toward the worse for aggressive and hyperactive behaviors because low SES children are more frequently exposed to stressful negative life events (Heckman, 2006) and show greater exposure to violence (Selner-O'Hagan, Kindlon, Buka, Raudenbush, \& Earls, 1998). As such, children in our sample are more at risk of developmental continuity of maladaptive behavior and school adjustment difficulties. Compared to non-disadvataged peers, they are more likely to enter the school system with well developed resources to meet their educational and socio-emotional needs (Carter et al., 2010). Nevertheless, despite the chances of supporting a null hypothesis - our results show early childhood behavioral improvement does have long-term value.

In this paper, we studied natural change. However, our findings have strong implications for contrived change resulting from interventions directed at behavioral change. This is promising to those who are concerned with improving children's behaviors in order to change their developmental outcomes. Developmental change is either natural (as studied here) or contrived (as suggested by our findings). Nevertheless, its impact underscores the necessity and the validity of early psychosocial interventions.

The developmental chain of behavioral risk that must be broken has been underscored in past research. Disruptive behaviors as aggression during preschool predict antisocial behavior at adolescence (Robins, 1966, Lyman et al., 2009). Moreover, characteristics associated with symptoms of attention deficit and hyperactivity disorder from childhood to adulthood could lead to problematic outcomes such as lower educational performance, lower attainment, and more school dropout. There is also higher probability of adult unemployment (Barkely, Fischer, Smallish, \& Fletcher, 2006; Véronneau et al., 2008). As such, prevention of antisocial behavior and underachievement should ideally start during early childhood (Heckman, 2006). Because these are more malleable than other behaviors, it is advantageous that such approaches in prevention address externalizing behaviors in general. Our results suggest that kindergarten represents a critical period for such change to occur and that effort to make such changes by teachers and mental health school personnel reap enormous benefits over the long-term.

This study is not without limitations. First, the social skills variable, measured by teacher reports of how children got along with their peers, was measured using one item. Because it represents the lowest lying fruit among more desirable multi-item, multi-source observations, this one item measure presents questions of validity. Nevertheless, the one-item measure was robust enough to predict peer affiliation, five to six years later. Second, this study is based on secondary data analyses, which implies that we used whatever data was available. The analyses might be limited by sample attrition, and it is conservative to assume that those who were not retained might be possibly more at-risk on some unmeasured characteristic. Because of this natural attrition, our sample was set up for failing to detect an effect (given our sample was less at-risk due to assumed attrition bias). We implemented ample controls for possible omitted variable bias, as has been recommended in the school readiness literature (Duncan et al., 2007). Nevertheless, our study seems to be compelling because of the size and characteristics of our sample. The fact that ability to get along with others is reliably linked with belonging to a popular, deviant, and rejected peer group suggests that it could likely be generalized to children from other low socioeconomic status families. Also, much like the approach used in Duncan et al. (2007), our use of a behavioral change model represents a noteworthy innovation in studying later peer relationships as a part of school readiness assessments in kindergarten. We urge others with similar data available for secondary analysis to further validate the influence of early behavioral change on peer affiliations in adolescence.

Although the majority of studies on this subject use sociometric measures, we encourage the use of multiple data sources to explore the robust nature and course of individual characteristics and later social relationships. Future research on how improvements in behavioral and emotional regulation in children affect later peer outcomes might shed light on critical periods for prevention strategies. Schools can offer specific classroom experiences 
adjusted to the characteristics of kindergarten children. Our results suggest that we could place more effort in the creation of intervention programs that specifically target hyperactive, aggressive, and attentive behaviors, given that these are relevant to later peer and deviance outcomes at the transition from elementary to secondary school (Gifford-Smith, Dodge, Dishion, \& McCord, 2005).

\section{References}

Barkley, R. A. (2012). Executive Functioning and Self-Regulation: Extended Phenotype, Synthesis, and Clinical Implications. New York: Guilford.

Barkley, R. A., Fisher, M., Smallish, L., \& Fletcher, K. (2006). Young adult follow-up of hyperactive children: Adaptive functioning in major life activities. Journal of the American Academy of Child and Adolescent Psychiatry, 45, 192-202.

Bukowski, W. M., Hoza, B., \& Boivin, M. (1993). Popularity, friendship, and emotional adjustment during adolescence. New Directions for Child Development, 60, 23-37.

Carter, A. S., Wagmiller, R. J., Gray, S. A., McCarthy, K. J., Horwitz, S. M., \& Briggs-Gowan, M. J. (2010). Prevalence of DSM-IV disorder in a representative, healthy birth cohort at school entry: Sociodemographic risks and social adaptation. Journal of the American Academy of Child and Adolescent Psychiatry, 49, 686-98.

children. Science, 312, 1900-1902.

Coie, J.D., Lochman, J.E., Terry, R., \& Hyman, C. (1992). Predicting early adolescent disorder from childhood aggression and peer rejection. Journal of Consulting and Clinical Psychology, 60, 783-792.

Collins, W. A. \& Van Dulmen, M. (2006). The significance of middle childhood peer competence for work and relationships in early adulthood. In A. Huston (Ed.), Developmental contexts in middle childhood (pp. 23-40). New York: Cambridge University Press.

Côté, S.M., Vaillancourt, T., LeBlanc, J.C., \& Tremblay, R. E. (2006). The development of physical aggression from toddlerhood to pre-adolescence: A nation-wide longitudinal study of Canadian children. Journal of Abnormal Child Psychology, 34, 71-85.

Dobkin, P.L., Tremblay, R.E., Mâsse L.C., \& Vitaro, F. (1995). Individual and peer characteristics in predicting boys' early onset of substance abuse: A 7-year longitudinal study. Child Development, 66, 1198-1214.

Duncan, G.J., Dowsett, C.J., Claessens, A., Magnusson, K., Huston, A., Klebanov, P., \& Japel, C. (2007). School readiness and later achievement. Developmental Psychology, 43, 1428-1446.

Dunn, L. M., Thériault-Whalen, C. M., \& Dunn, L. M. (1993). Échelle de vocabulaire en images Peabody. Adaptation française du Peabody Picture Vocabulary test-revised. Manuel pour les formes A et B (Stardardized French version of the Peabody Picture Vocabulary Test). Toronto, ON: Psycan.

Erdley, C. A., Nangle, D. W., Newman, J. E., \& Carpenter, E. M. (2001). Children's friendship experiences and psychological adjustment: Theory and research. In D. W. Nangle \& C. A. Erdley (Eds.), New directions for child development: No 91. The role of friendship in psychological adjustment (pp. 5-23). San Francisco, CA: Jossey-Bass.

Garon, N., Bryson, S. E., \& Smith, I. M. (2008). Executive function in preschoolers: A review using an integrative framework. Psychological Bulletin, 134, 31-60.

Gifford-Smith, M., Dodge, K.A., Dishion, T.J., \& McCord, J. (2005). Peer influence in children and adolescents: Crossing the bridge between developmental and intervention science. Journal of Abnormal Child Psychology, 33, 255-265.

Goldstein, S. E., Davis-Kean, P. E., \& Eccles, J. S. (2005). Parents, peers, and problem behavior: A longitudinal investigation of the impact of relationship perceptions and characteristics on the development of adolescent problem behavior. Developmental Psychology, 41(2), 401-413.

Heckman, J. J. (2006). Skill formation and the economics of investing in disadvantaged .

High, P. C., \& the Committee on Early Childhood, Adoption, and Dependent Care and Council on School Health. (2008). School readiness. Pediatrics, 121, 1008-1015.

Jessor R. (1998). New perspectives on adolescent risk behavior. New York, NY: Cambridge University Press.

Kerr, M.A., Tremblay, R.E., Pagani, L.S., \& Vitaro, F. (1997). Boys' behavioral inhibition and the risk of later delinquency. Archives of General Psychiatry, 54, 809-816. 
Ladd, G. W. (1990). Having friends, keeping friends, making friends, and being liked by peers in the classroom: Predictors of children's early adjustment? Child Development, 61, 1081-1100.

Loeber, R., \& Stouthamer-Loeber, M. (1998). Development of juvenile aggression and violence: Some common misconceptions and controversies. American Psychologist, 53, 242-259.

Lyman, D. R., Charnigo, R., Moffitt, T. E., Raine, A., Loeber, R., \& Stouthamer-Loeber, M. (2009). The stability of psychopathy across adolescence. Development and Psychopathology, 21, 1133-1153.

Okamoto, Y., \& Case, R. (1996). Exploring the microstructure of children's central conceptual structures in the domain of number. In R. Case \& Y. Okamoto (Eds.), The role of central conceptual structures in the development of children's thought. Monographs of the Society for Research in Child Development, 60, 27-58.

Pagani, L. S., Japel, C., Larose, S. Vitaro, F., Tremblay, R. E., \& McDuff, P. (2007). When predictions fail: The case of unexpected pathways towards high school drop out. Journal of Social Issues, 64, 175-193.

Pagani, L., Fitzpatrick, C., Archambault, I., \& Janosz, M. (2010). School Readiness and Later Achievement: A French Canadian Replication and Extension. Developmental Psychology, 46(5), 984-994.

Parker, J. G., \& Asher, S. R. (1987). Peer relations and later personal adjustment: Are low-accepted children at risk? Psychological Bulletin, 102, 357-389.

Robins, L. N. (1966). Deviant children grown up: a sociological and psychiatric study of sociopathic personality. Baltimore, MD: Williams \& Wilkins.

Ruff, H. A., \& Rothbart, M.K. (1996). Attention in early development. New-York: Oxford University Press.

Selner-O’Hagan, M. B., Kindlon, D. J., Buka, S. L., Raudenbush, S., \& Earls, F. (1998). Assessing exposure to violence in urban youth. Journal of Child Psychology and Psychiatry, 19, 215-224.

Shonkoff, J., \& Phillips, D. (2000). From Neurons to Neighbourhoods: The Science of Early Childhood Development. Washington: DC: National Academy Press.

Tremblay, R. E., Pihl, R. O., Vitaro, F., \& Dobkin, P. (1994). Predicting early onset of male antisocial behavior from preschool behavior. Archives of General Psychiatry, 51,732-739.

Véronneau, M. H., Vitaro, F., Pederson, S., \& Tremblay, R. E. (2008). Do peers contribute to the likelihood of secondary school graduation of disadvantaged boys? Journal of Educational Psychology, 2, 429-442.

Vitaro, F., Brendgen, M., Larose, S., \& Tremblay, R. E. (2005). Kindergarten disruptive behaviors, protective factors, and educational achievement by early adulthood. Journal of Educational Psychology, 97, 617-629.

Table 1. Descriptive statistics of kindergarten cognitive, behavioral, and social skills predictors and peer affiliation outcomes by the end of elementary school

\begin{tabular}{|c|c|c|}
\hline Variables & Mean & Standard deviation \\
\hline \multicolumn{3}{|l|}{ Kindergarten Predictors } \\
\hline Sex & 1.50 & 0.50 \\
\hline Family Configuration & 1.77 & 0.42 \\
\hline Maternal Education & 7.26 & 16.27 \\
\hline NKT & 13.21 & 3.79 \\
\hline PPVT & 59.55 & 24.13 \\
\hline Hyperactive Behavior & 12.88 & 2.84 \\
\hline Inattentive Behavior & 6.22 & 2.49 \\
\hline Prosocial Behavior & 18.22 & 5.11 \\
\hline Emotionally-Distressed & 13.44 & 2.02 \\
\hline Physically Aggressive & 16.90 & 2.82 \\
\hline Social Skills & 2.01 & 1.00 \\
\hline \multicolumn{3}{|c|}{ End of Elementary School Outcomes } \\
\hline Popular Peer Affiliations & 1.77 & 0.55 \\
\hline Deviant Peer Affiliations & 2.61 & 0.54 \\
\hline Rejecting Peer Affiliations & 2.69 & 0.53 \\
\hline
\end{tabular}


Table 2. Bivariate correlations

\begin{tabular}{|c|c|c|c|c|c|c|c|c|c|c|c|c|c|c|}
\hline Variables & 1 & 2 & 3 & 4 & 5 & 6 & 7 & 8 & 9 & 10 & 11 & 12 & 13 & 14 \\
\hline 1. Hyperactive & - & & & & & & & & & & & & & \\
\hline 2. Inattentive & $.670 * *$ & & & & & & & & & & & & & \\
\hline 3. Prosocial & $.219 * *$ & $.243 * *$ & & & & & & & & & & & & \\
\hline 4. Aggressive & $.615^{* *}$ & $.383 * *$ & $.211 * *$ & & & & & & & & & & & \\
\hline 5.Emot.-Distress & $.282 * *$ & $.341 * *$ & $.161 * *$ & $.250^{* *}$ & & & & & & & & & & \\
\hline 6. Social skills & $-.504 * *$ & $.422 * *$ & $.259 * *$ & $.486^{* *}$ & $.211 * *$ & & & & & & & & & \\
\hline 7. Deviant Peers & $.317 * *$ & $.231 * *$ & $.118^{* *}$ & $.302 * *$ & .065 & $.330 * *$ & & & & & & & & \\
\hline 8. Popular Peers & $.247 * *$ & $.278^{* *}$ & $.145^{* *}$ & $.165^{* *}$ & -.054 & $.324 * *$ & $.157 * *$ & & & & & & & \\
\hline 9.Rejected Peers & $.263 * *$ & $.250 * *$ & $.125 * *$ & $.184 * *$ & .065 & $.311 * *$ & $.190 * *$ & $.471 * *$ & & & & & & \\
\hline 10. NKT & $.132 * *$ & $.283 * *$ & $.135 * *$ & $.057^{*}$ & $.095 * *$ & $.137 * *$ & .038 & $.217 * *$ & $.126^{* *}$ & & & & & \\
\hline 11. PPVT & .028 & $.113 * *$ & $.199 * *$ & .009 & .019 & -.036 & -.038 & -.064 & .003 & $.446^{* *}$ & & & & \\
\hline 12. Sex & $.286^{* *}$ & $.211 * *$ & $.211 * *$ & $.211 * *$ & .046 & $.170 * *$ & $.237 * *$ & -.033 & .069 & .054 & .037 & & & \\
\hline 13.Fam. Config. & $.087 * *$ & $.103 * *$ & -.017 & $.088^{* *}$ & $.087 * *$ & $.129 * *$ & $.132 * *$ & -.059 & .059 & -.018 & $.065^{*}$ & .041 & & \\
\hline 14Maternal Educ. & -.006 & .006 & .064 & .032 & $.073 *$ & -.064 & .046 & -.016 & .002 & -.065 & $.085^{*}$ & .015 & .005 & \\
\hline
\end{tabular}

Table 3. The prospective relationship between ability to get along with peers, rated by kindergarten teachers, and later peer affiliations

\begin{tabular}{|lr|l|l|l|l|}
\hline Variables & & $\begin{array}{l}\text { Standardized Beta }(\beta) \\
\text { coefficient }\end{array}$ & SE & $\mathrm{R}$ & $\mathrm{R}^{2}$ \\
\hline $\begin{array}{l}\text { Popular } \\
\text { Affiliations }\end{array}$ & Peer & $.25^{* *}$ & .91 & $.42^{* *}$ & $.18^{* *}$ \\
\hline $\begin{array}{l}\text { Deviant } \\
\text { Affiliations }\end{array}$ & Peer & $-.18^{* *}$ & .93 & $.41^{* *}$ & $.17^{* *}$ \\
\hline $\begin{array}{l}\text { Rejected } \\
\text { Affiliations }\end{array}$ & Peer & $-.24^{* *}$ & .95 & $.40^{* *}$ & $.16^{* *}$ \\
\hline
\end{tabular}

Note. ${ }^{* *}$ Beta is significant at the $\mathrm{p}<.01$ level (2-tailed)

Table 4. Descriptive statistics for change scores generated from the beginning to the end of kindergarten

\begin{tabular}{|l|l|l|}
\hline Variables & Mean & Standard deviation \\
\hline Hyperactive Behavior & 0.08 & 2.21 \\
\hline Inattentive Behavior & -0.16 & 2.21 \\
\hline Prosocial Behavior & 1.42 & 5.07 \\
\hline Aggressive Behavior & 0.32 & 2.23 \\
\hline Emotional-Distress & 0.74 & 2.02 \\
\hline
\end{tabular}


Table 5. The prospective association between developmental change in kindergarten behaviors and later peer affiliation characteristics at the end of elementary school

\begin{tabular}{|l|l|l|}
\hline Popular Peer Affiliation & Standardized Beta $(\beta)$ coefficient & SE \\
\hline Hyperactive Behavior & $-0.15^{* *}$ & .91 \\
Inattentive Behavior & $0.17^{* *}$ & \\
Prosocial Behavior & 0.02 & \\
Aggressive Behavior & -0.03 & \\
Emotional-Distress & -0.03 & \\
\hline Deviant Peer Affiliation & Standardized Beta $(\beta)$ coefficient & SE \\
\hline Hyperactive Behavior & $0.13^{* *}$ & .91 \\
Inattentive Behavior & -0.02 & \\
Prosocial Behavior & -0.05 & \\
Aggressive Behavior & $0.13^{* *}$ & \\
Emotional-Distress & -0.01 & \\
\hline Rejecting Peer Affiliation & Standardized Beta $(\beta)$ coefficient & SE \\
\hline Hyperactive Behavior & $0.11^{*}$ & .91 \\
Inattentive Behavior & $-0.13^{*}$ & \\
Prosocial Behavior & -0.03 & \\
Aggressive Behavior & 0.08 & \\
Emotional-Distress & 0.03 & \\
\hline
\end{tabular}

Notes. (1) models include baseline child and family controls. $(2) *$ indicates that the Beta coefficient is significant at the $\mathrm{p}<.05$ (2-tailed) and $* *=$ Beta coefficient is significant at the $\mathrm{p}<.01$ (2-tailed) 